\title{
Barriers in Diabetes Self-management: A Qualitative Study from the Perspective of Nurses in Primary Health Centers, Indonesia
}

\author{
Atyanti Isworo*(D), Yunita Sari, Annas Sumeru, Nuriya Nuriya \\ Department of Nursing Science, Faculty of Health Sciences, Jenderal Soedirman University, Purwokerto, Indonesia
}

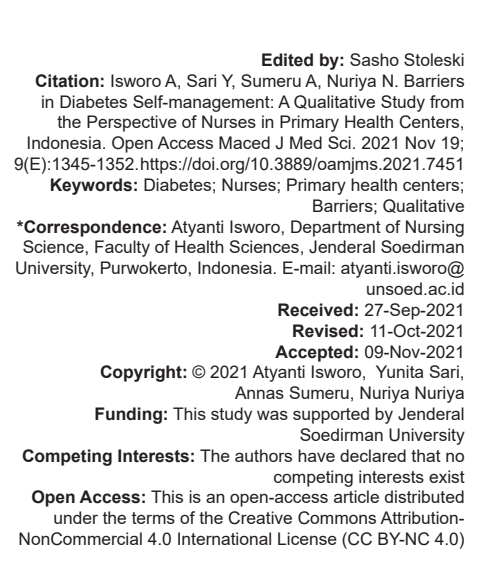

Introduction

A chronic disease is considered to be a disease that lasts for a very long time and is usually incurable. The disease is a major contributor to emotional instability and can affect the patient physically, which further can lead to death [1]. Diabetes is a chronic disease with high incidence rates. The International Diabetes Federation in 2019 revealed that there are 463 million of diabetic people in the world, of which 88 million are in Southeast Asia [2]. The number of cases has increased by 38 million people in the world compared to 2018 . The number of people estimated to have diabetes by 2045 is 700 million people across the world [2]. The prevalence of people with diabetes in Indonesia has reached to $2.0 \%$ of its total population, with the age category of 55-64 years having the highest number of people with diabetes. In Central Java, the number of people with diabetes aged $\geq 15$ years reached to 2.1 million in 2018 [3].

Diabetes management focuses on "maintaining blood glucose regulation within a normal range" otherwise known as self-care. Diabetes self-care is an individual's ability to manage symptoms, treatment, physical and psychological consequences, and lifestyle changes that are inherent in the life of a person with diabetes [5]. Forms of self-care activities include nutrition regulation, physical exercise, medication, selfmonitoring of blood glucose, and foot care [6]. Glycemic control is often used to measure health outcomes in diabetic patients. Research from Healy et al. (2013) showed that maintaining blood glucose near to normal levels can reduce the risk of diabetes complications [4].

Many diabetic patients are unable to perform self-care as recommended and become frustrated, which manifests in the form of noncompliance or disobedience in taking care of themselves. Bonger et al. (2018) in his study reported that $75.9 \%$ of diabetic patients did not adhere to dietary recommendations, $83.5 \%$ of patients ignored self-monitoring blood glucose, $4.3 \%$ of patients did not comply with prescribed drugs, $23-52 \%$ of patients had poor foot care, and $70-81 \%$ of the patients did not adhere to physical exercise [7]. Other studies also revealed that adherence to selfcare activities including diet and physical exercise was relatively poor, while patients were more adherent to taking medication [8]. Other studies stated that the average patient nonadherence to correct diet according to meal planning was $35-75 \%$, inappropriate insulin use was $20-80 \%$, inaccuracy in recording blood sugar checks was $30-70 \%$, poor foot care was $23-52 \%$, and nonadherence to physical exercise ranged from 70 to $81 \%$ [9]. 
Many factors contribute to low selfcare adherence of diabetic patients, including socioeconomic status, diabetes education, health beliefs, education level, family history of diabetes, and patient demographic characteristics [10]. The first step to changing patients' habits into adopting a healthier lifestyle is using education from health workers. However, several barriers were found by health workers when attempting to change patients' lifestyles, such as: difficulties in making patients understand diabetes and motivating them to change their lifestyle to a healthier one; patient non-adherence to diet and medication; and weight control [11], [12]. Other barriers external to patients include inadequate health worker incentives, insufficient nursing time, and lack of manpower [13].

\section{Background}

The Indonesian government has also made efforts to prevent and control diabetes through strengthening the role of primary health centers (puskesmas). Good collaboration between health providers working in puskesmas, particularly nurses who are the majority of health workers in puskesmas, and diabetic patients can improve patients' compliance in implementing diabetes self-management. It is worth noting that nurses have a key role in educating diabetic patients and encouraging them in the self-management of their diabetic care. Therefore, it is necessary to reduce the barriers faced by nurses in managing diabetic patients' self-management. Unfortunately, there has been no research in Indonesia to date that examines the barriers faced by nurses in the self-management of diabetes mellitus (DM) patients.

In Indonesia, there is an integrated coaching program (posbindu), where health workers from the puskesmas, in collaboration with health cadres (health volunteers) in the village, do home visitation to diabetic patient residents and perform blood pressure monitoring, blood sugar level monitoring, and body mass index measurements as a reference before patients conduct counseling with the general practitioners in puskesmas. In addition, there is a chronic disease management program called Prolanis, which is intended for people who have a health insurance card. During the program Prolanis participants will receive treatments, such as laboratory examinations and routine drugs, where all costs are covered by BPJS (health insurance). Prolanis also provides counseling to improve the quality of health for patients suffering from non-communicable diseases, one of which is DM. The number of activities conducted by public health nurses working in puskesmas can cause barriers in diabetes management. Therefore, the purpose of this study is to explore the barriers faced by nurses in managing the self-management of DM patients.

\section{Method}

This research is a qualitative research with a phenomenological descriptive approach designed to seek and reveal the experiences of nurses regarding the barriers in encouraging diabetic patients' self- management. The data were collated using the Focus Group Discussion (FGD) technique, which was conducted from May to July 2021 at the Department of Nursing, Fikes Unsoed.

\section{Study sample and data collection}

The study participants were nurses at puskesmas in urban and suburban areas who were recruited using a purposive sampling technique. The inclusion criteria included nurses who have been responsible for managing diabetes for at least a year, nurses who have the minimum degree of a diploma 3 or bachelor (known as "Ners"), and who were willing to be a participant. The selection of participants began with visitation to puskesmas in urban and suburban areas. The researcher asked permission from the head of the puskesmas and explained the purpose of the study and the nurse criteria for them to become important informants. The head of the puskesmas provided the recommendations for those nurses who are responsible for diabetes management. Researchers met the potential participants who were eligible according to the research criteria, then explained the research objectives and research procedures to the prospective participants, as well as obtaining approval for research involvement. From this, the researchers obtained 10 nurses of which 5 nurses were from urban health centers and 5 nurses were from suburban health centers. The chosen participants were invited to the Department of Nursing, Jenderal Soedirman University, for both the first and second FGD sessions.

This study has received ethical approval from the Faculty of Health Sciences ethics committee with the number 345/EC/KEPK/IV/2021, and this research has also received a permit from the Banyumas District Health Office with the number 070.1/082/III/2021.

A FGD was implemented to explore the barriers felt by nurses in the management of diabetic patients' self-care. Due to the data collection being conducted during the COVID-19 pandemic, from May to June 2021, strict health protocols were applied. All participants as well as the interviewers had received the first and second doses of the COVID vaccine, all FGD participants were required to wear masks and wash their hands, and a room was used with good ventilation (the windows were opened). The seating arrangement was a semicircle with a distance between participants of $1.5 \mathrm{~m}$ and a voice recorder was placed in the middle.

When collecting data, the two researchers explained the purpose and procedure of the FGD. The 
researcher who acted as the interviewer sat at the front while the other researchers were tasked with observing and recording the FGD.

The researchers had created a guideline for the FGD, which consisted of the objectives of the FGD, the criteria of participants, the material to be the focus of the discussion, the time and location of the implementation, and the rules of the FGD. The focus of the discussion included: (1) diabetes trends in puskesmas; (2) puskesmas' programs for diabetes; (3) available facilities for dealing with diabetes in puskesmas; (4) examples of management of diabetes that has been done successfully; (5) problems and barriers in diabetes management; (6) potential and opportunities for diabetes management; and (7) suggestions and expectations for diabetes management.

The FGD was conducted twice for each group, which lasted for $90 \mathrm{~min}$ and $45 \mathrm{~min}$ for the first and second FGD, respectively. In the second FGD, participants were able to add or subtract information from the first FGD. However, no new information was generated from the participants during the second FGD.

\section{Data analysis}

The FGDs were transcribed from the audio recordings and notes taken during the FGDs. An inductive approach to determining the theme was used to analyze the data. Data analysis was done by organizing the data into keywords, and then it was categorized to determine the themes. Furthermore, the seven steps of data analysis developed by Colaizzi [14] were applied in this study, including: (1) the main author made a transcript of the interview by listening to the recording and combining it with field observations; then the transcripts were reviewed several times by the main author and co-authors. The results of this transcript were also returned to the participants to get input on the correctness of the written transcripts; (2) the transcripts were validated by participants, reviewed by the main author, and key words were identified; (3) the identified keywords were arranged into temporary categories and subthemes by the main author; and (4) the main author and co-authors discussed the results of the initial categories and subthemes several times. All authors checked the suitability of the subthemes by reviewing the keywords to ensure the integration of the subthemes; (5) The subthemes were organized into themes; (6) The main author then wrote down these themes completely, clearly, and systematically; and finally, (7) the last step was to relay the findings to the participants.

\section{Trustworthiness}

The transcript and emerging themes of the FGD results were returned to the participants using the online media, the Zoom platform, to ensure credibility. The participants read and confirmed that the transcript was an accurate representation of the participants' experiences.

Dependability in this study was carried out by involving the reviewer of the data and supporting documents as well as involving an external reviewer - YS who is an expert on diabetes. The main author also did confirm ability by discussing all transcripts, initial theme categorization, and theme analysis tables with the external reviewer YS. The transferability process was carried out by making reports that provide detailed and clear, systematic, and reliable descriptions.

\section{Results and Discussion}

\section{Characteristics of participants}

Ten participants took part in this study with ages varying from 25 to 56 years. Eight participants had gained the Diploma 3 nursing education level, and two participants had bachelor's degrees. Experience in diabetes management also varied from 1 to 18 years. There were nine female nurses and one male nurse. The themes obtained from this study were (1) barriers from within the diabetic patients and (2) barriers external to the diabetic patients.

\section{Theme 1: Barriers from within the Patient}

\section{Subtheme 1: Fear of knowing about the disease and the stigma associated with diabetes}

Fear of knowing and being known to have diabetes is reported as a barrier in the self-management of diabetic patients. Participants described that diabetic patients feel afraid if they know that they have acquired diabetes. Diabetes has become a stigma in society, so they worry that their offspring/family will be labeled as a family of diabetics.

"Most people are still feeling the fear of getting caught by the disease, so they have come to posbindu but do not want to have their blood sugar checked, even though it's free. They are more afraid of finding out about their disease." - (suburban nurse, female).

"Hence, if they caught having diabetes, they got scared" - (rural nurse, female)

"Sometimes, we feel that DM has a bad stigma. They feel that DM is a hereditary disease. Thus, later, if someone is caught with having DM, their descendants will be branded. In our place, there is a lot of people who still think so. Therefore, when someone was checked and the results came back that they have DM, they didn't want it to be published." - (suburban nurse, male). 
"Yes, they feel that DM is a hereditary disease, not because of behavior. Yes, it is not big, but it appears like that, so they are worried about getting a bad label in society". - (rural nurse, female).

\section{Subtheme 2: Fear and distrust of health}

\section{cadres}

Patients are afraid of health workers and do not trust health cadres. At the medical examination conducted by health cadres, some patients are reluctant to be examined by health workers

"Well, at my place, the cadre's program is actually ongoing; the problem is there are many patients who don't want to be checked by the cadre. So, uh well it's the same" - (rural nurse, female).

"In the city, they (patients) don't want to get their blood pressure checked by the cadre. They didn't believe them, while it's actually the same if we (nurses) check on them." - (suburban nurse, female).

"So actually, at my place, we (nurses) have given out our best efforts to approach the community, there's posbindu, which involves the health cadres, but some of them are still afraid of the cadres and of us (nurses)." - (suburban nurse, female).

\section{Subtheme 3: Low awareness and feeling healthy}

In this study, it was found that patients of productive age were considered to have low consciousness. They rarely checked themselves at posbindu or puskesmas. In addition, many patients felt well. DM is a chronic disease, where the signs and symptoms are not always visible, so many patients feel healthy. Moreover, when the blood sugar level examination is normal, the patient will feel that they are healthy.

"For activities such as posbindu, nurses, and midwives collaborate.... Most of the people who come are the elderly; the productive ones are even less."(rural nurse, female).

".... afraid of being stigmatized. Hence, in the end, the participants in posbindu are just the elderly. Hence, it's like a program for the elderly. Those who are of productive age don't want to come anymore, it's hard to feel that there are no symptoms, that means they are healthy - (suburban nurse, female).

"Yes, productive age patients still feel healthy" - (rural nurse, female).

“... patients don't feel sick." - (suburban nurse, male).

"In our own puskesmas, it is difficult to move patients aged 20-59 years. Most of them are still working, so we hold a posyandu. Indeed, most of those present are the elderly, those who are of productive age, absolutely no one comes. The difficulty is that it is difficult to move those of a productive age. Those who come are again. Most women, men rarely want to attend."- (suburban nurse, female).

\section{Subtheme 4: Lack of self-care management responsibility}

Lack of responsibility for self-care management and difficulty in changing routines/habits to follow the recommended diabetes management resulted in patients' noncompliance in DM self-management.

"Diagnosed DM patients have a bad adherence to taking medication and following dietary recommendations." - (suburban nurse, male).

"The difficult one, patients with insulin. Even though they got a gradually increased dose of insulin, every time we checked their blood glucose level, the result tends to rise. The patients said that they too want their blood glucose level back to normal, but their awareness is low, they still want to have good food. They think they already consume the medication, so they can eat whatever food they want." - (suburban nurse female).

"Basically, his (patient's) behavior can't change. We (nurses) already educated him, nutritionists also educated him, we also referred him to a hospital, so what else can we do, why won't he change?" - (suburban nurse, female).

"They consume medicine, but they don't follow the diet recommendations." - (rural nurse, female).

"There is a patient who has been prescribed medicine and insulin with a full dose of 30, but he always eats 2 portions (a lot)." - (suburban nurse, female).

"A patient said, "well, the food is tasty, why can't I eat it, what's important is I already got my insulin injection." They feel assured if they have their insulin injections." (Rural nurse, female).

"Sometimes, there are students doing research, when they do the research, the patients' awareness reappears, but when the research is done, the patients behavior is back to their usual selves." - (suburban nurse, female).

"It's hard because when we visit them, they just say yes (they show that they understand). We checked their daily menu according to the diet recommendations, but it doesn't last very long, because eventually the patients go back to their old habits" - (suburban nurse, female).

"DM patients don't die right away, and sometimes show no symptoms at all, so that's why they are not obedient." - (suburban nurse, female)

"The patients' independence is at the $3^{\text {rd }}$ level, they did what we (nurses) told but it doesn't last very long."- (rural nurse, female). 


\section{Subtheme 5: Time constraints}

The problem of the timing for diabetes management activities was also a barrier found in this study. Many diabetic patients are still working and therefore when diabetes management activities are held during working hours, few diabetic patients will attend.

"Sometimes they give out excuses like it is their work time so they can't come. So usually those who come are housewives, their husbands won't come because of work." -- (rural nurse, female).

However, nurses have tried to change the diabetes management activities to be on a day off, but many patients are still reluctant to attend.

"Sometimes we change it to the weekend or their day off, still there's no one coming. Hence, we're a little confused." - (rural nurse, female).

\section{Theme 2: Non-patient (external) Factors}

\section{Subtheme 1: Limited manpower}

The limitations of both health and administrative personnel were revealed in the study.

"Less effective due to various factors, one of them is the lack of manpower." (Rural nurse female)

"Hence, the patients can't directly accept the lifestyle changes we explained to them, and after that some of them won't come to puskesmas again. Well in theory, we should've visited them. However, is it possible at my place?" - (suburban nurse, female).

"At my place, we visit DM patients. However, we visited only once because the lack of manpower." (Rural nurse, female)

"Actually, our human resources have increased, but the workload is also increasing." - (suburban nurse, female).

\section{Subtheme 2: Limited facilities and funding problems}

Limited facilities such as a lack of laboratory equipment and materials were also expressed by several participants.

"And also, the lack of equipment, because there are rules if we want to buy something." - (rural nurse, female).

"For example, we want to buy blood glucose test strips, and it depends on each puskesmas' policy. At my place, every time we propose to buy the strip, they can't directly allow it, even though we really need it." - (rural nurse, female).
"We've coordinated that with the village. There are several villages that are willing to help, but some are not. Not every village was willing to help. In our area, there are 2 villages that are willing to help in providing blood glucose test strips, but the other 5 can't help us because their funding has been allocated for other things." - (suburban nurse, female).

\section{Subtheme 3: Many programs}

The participants revealed that the programs or activities they carried out were not limited to diabetes, but also included other chronic diseases. The documentation system is also the responsibility of the nurse.

"At puskesmas there are few nurses, midwives have also worked on $\mathrm{MCH}$ (mother and child health), immunization, and others. Nurses also have to come to posbindu, even though we (nurses) have shifts at the polyclinic, too, there are also a lot of reports to do." - (suburban nurse, female).

"As much as we'd like to do home visits, there are so many activities to do so we can't always come. For example, if a diabetic patient didn't come to do check-up at puskesmas, we should visit them, but if it happens continuously or in large numbers, we also become overwhelmed." - (rural nurse, female).

"Actually, we as health workers have done our best. However, there are so many targets and so many programs to do."- (suburban nurse, male).

\section{Discussion}

This qualitative study explores the perceived barriers of nurses at puskesmas in managing diabetic patients. Barriers felt by nurses in managing diabetic patients come from both inside and outside the patients. Barriers of DM patients include fear of being exposed to the disease and stigma associated with diabetes, fear and distrust of health cadres, low awareness and feeling healthy, time constraints for patients, and diabetes selfmanagement responsibilities. Meanwhile, external barriers for DM patients are limited manpower, limited facilities and finances, and the workload at puskesmas.

DM requires long-term care and awareness of the patients themselves to manage the disease. Therefore, our study highlights that the lack of accountability for diabetes self-management practices is an important barrier to diabetes management. This is in accordance with the research of [15], which stated that patient preferences and the patient's ability to change behavior are barriers in diabetic care. In addition, other studies revealed that eating habits are also a barrier in following a diabetic diet. Participants found it was 
very difficult to change patient habits because they had been used to it since childhood [16], [17], [18]. Lack of responsibility in diabetes self-management practices can be influenced by knowledge. The results of this study also imply that diabetic patients have poor knowledge about diabetes self-management. As the participants stated that patients would ignore food recommendations if they took medication or insulin. Diabetic patients need to be responsible for managing their own health. Taking responsibility for one's own health enables patients to manage diabetes, facilitated by knowledge of self-management practices. This is in line with previous research, which stated that the factor that facilitates the practice of diabetes self-management is the patient's responsibility toward his own body [19]. The person in charge will be motivated to learn in-depth information about the disease and its management.

In this research, there is evidence that nurses have provided education to patients. However, whether this is education that is accompanied by building motivation, self-efficacy, eliminating fear, and stigma associated with diabetes has not been fully explored in this study. Participants only revealed that they had provided education and sometimes carried out home visitation. Building patient motivation and self-efficacy is important, considering that diabetes requires long-term and continuous self-management efforts throughout life. Participants revealed that patients will follow diabetes management according to recommendations but only temporarily, not for long. This indicates the need for continuous motivation for diabetic patients and building patient self-efficacy regarding diabetes self-management. Therefore, it is important for nurses to be able to recognize the condition of patients who have experienced decreased motivation, as well as the lack of self-efficacy in diabetic patients. Provision of knowledge through training and seminars about the psychosocial impact of diabetes and how to overcome it needs to be given to nurses in puskesmas.

This study also revealed that the barriers to diabetes management were the patient's lack of awareness and the perception that they were healthy. Perceived severity has an important role in explaining health-related behaviors and improving preventive action. Attitudes and beliefs are important factors influencing perceptions of susceptibility and disease severity. Similar research also stated that personal perception is associated with awareness of the importance of physical exercise [20]. Research [21] also reported that patient attitudes have an important role in patients' willingness to adhere to diabetes management. Feelings of fear of knowing they have the disease and stigma are other barriers to DM selfmanagement practice and can affect patients with chronic medical conditions. Perceived stigma is when someone believes that others perceive them differently and respond to them unfairly [22]. Diabetic patients will experience restrictions such as getting insulin injections, blood glucose monitoring, dietary restrictions, obesity, and hypoglycemic episodes, which can all contribute to the experience of diabetes stigma. The psychosocial impact of diabetes stigma is that patients feel fear, shame, self-blame, anxiety, and low self-esteem [23], [24]. These psychosocial conditions can lead to depression and are correlated with a decrease in diabetes self-management behavior and an increase in diabetes complications [25], [26], [27]. Based on the results of this study, we recommend further exploration regarding the stigma experienced by diabetic patients. Given the stigma associated with diabetes, diabetic patients are very likely to avoid medical examinations. Research by Browne et al. [28] revealed that in many cases, diabetic patients avoid disclosing their disease to friends, health cadres, and health workers because they are afraid of being judged or blamed. This stigma can lead to patient distrust of health cadres. In addition, health cadres may not undergo formal education as health workers but are trained in health and are extensions of puskesmas, which can increase the distrust from patients. Patients may assume that the cadres lack knowledge and skills compared to nurses or other health workers. Our findings underscore that the need for continuous training for health cadres is a crucial aspect in diabetes management.

This study also found that many patients do not attend diabetes management activities at posbindu. This is because some patients are still working so they cannot participate in health monitoring activities. As in the research of [29], lack of time due to work has a negative impact on following recommendations or attending appointments for health checks. However, in this study, it was revealed that the time of monitoring activities for health conditions had been changed to holidays, but still many patients did not follow the activities. Different strategies may be needed to tackle this situation, one of which is by home visitation or the use of social media (such as WhatsApp, Line, or Short Message Service) to monitor health conditions, provide education, and increase the motivation of diabetic patients. From the results of the monitoring through social media, the nurse can make a home visitation if it is needed. This strategy has the potential to save nurses' time, particularly when there is a shortage of personnel at the puskesmas.

The number of diabetic patients in one puskesmas in Indonesia varies widely. In this study, the average number of diabetic patients was 80 people (who regularly participated in activities at the puskesmas). The number of nurses in charge of diabetes management is around 2-3 people, but in Indonesia, public health nurses who are responsible for diabetes management do not only focus on handling diabetes cases. This is because the diabetes management program is integrated with the management of other chronic diseases such as hypertension, heart disease, stroke, or cancer. Therefore, public health nurses have workloads and finally they 
are often delayed in attending the diabetes programs. According to the research of [30], it was revealed that the inadequacy of personnel, both clinical and administrative personnel, is a barrier to achieving effective diabetes management in primary health centers.

Furthermore, the dependence of puskesmas on the central government often results in irregularities in the stock of medicines, laboratory equipment, and laboratory materials. This situation also hinders diabetes management. The findings of this study are in line with the research by [31], which stated that the challenges of diabetes management in primary health care are related to infrastructure and logistics.

\section{Limitation of study}

The research was conducted using qualitative methods and primary data obtained through FGD. Limitations in this study include the subjectivity of the researcher. Although the researcher has conducted a process of reviewing the literature, continuously discussing with other research members who are experts in the field of diabetes and experts in qualitative research, and confirming back with the participants, this is very much dependent on the researcher's interpretation of the meaning implied in the interview, so it is difficult to avoid bias.

\section{Conclusion}

In the management of diabetes, good collaboration between patients and health workers is essential. Effective diabetes management can be achieved through a holistic approach with adequate facilities at puskesmas. However, nurses face several barriers in achieving effective diabetes management. Lack of manpower, limited facilities, and finances, the workload and responsibility of diabetes nurses are all barriers that arise from within the puskesmas organization itself. Meanwhile, the lack of responsibility and commitment of patients to the self-management of diabetes and the psychosocial impact of diabetes are other barriers that are also faced by the nurses. It requires the cooperation of all parties, including health workers, patients, families, and the government to minimize these barriers.

\section{Acknowledgment}

The researchers would like to thank the participants and the head of the puskesmas for their participation in this study. We also express our gratitude to the research institute and community service of Jenderal Soedirman University for funding this research.

\section{References}

1. Megari K. Quality of life in chronic disease patients. Health Psychol Res. 2013;1(3):e27. https://doi.org/10.4081/hpr. 2013.e27

PMid:26973912

2. International Diabetes Federation. IDF Diabetes Atlas. $9^{\text {th }}$ ed. Brussels, Belgium: International Diabetes Federation; 2019.

3. Ministry of Health Republic of Indonesia. World Diabetes day 2018. World Diabetes day 2018. Indonesia: Information and Data Centers of Ministry of Health Republic of Indonesia RI; 2018. p. 1-8.

4. Healy SJ, Black D, Harris C, Lorenz A, Dungan KM. Inpatient diabetes education is associated with less frequent hospital readmission among patients with poor glycemic control. Diabetes Care. 2013;36(10):2960-7. https://doi.org/10.2337/ dc13-0108

\section{PMid:23835695}

5. Sigurðardóttir ÁK. Self-care in diabetes: Model of factors affecting self-care. J Clin Nurs. 2005;14(3):301-14. https://doi. org/10.1111/j.1365-2702.2004.01043.x

PMid: 15707440

6. Schmitt A, Gahr A, Hermanns N, Kulzer B, Huber J, Haak T. The diabetes self-management questionnaire (DSMQ): Development and evaluation of an instrument to assess diabetes self-care activities associated with glycemic control. Health Quality Life Outcomes. 2013;11:138. https://doi. org/10.1186/1477-7525-11-138

PMid:23937988

7. Bonger Z, Shiferaw S, Tariku EZ. Adherence to diabetic self-care practices and its associated factors among patients with Type 2 diabetes in Addis Ababa, Ethiopia. Patient Prefer Adherence. 2018;6(12):963-970. https://doi.org/10.2147/PPA.S156043 PMid:29922042

8. AlhaitiAH, Senitan M, Dator WL, Sankarapandian C, Baghdadi NA Jones LK, et al. Adherence of Type 2 diabetic patients to selfcare activity: tertiary care setting in Saudi Arabia. J Diabetes Res. 2020;2020:4817637. https://doi.org/10.1155/2020/4817637 PMid:33083495

9. Skarbek EA. Psychosocial Predictors of Self-care Behaviors in Type 2 Diabetes Mellitus Patient: Analysis of Social Support, Self-efficacy, and Depression. (Texas Tech University Health Science Center). United States: Texas Tech University; 2006. Available from: http://www.citeseerx.ist.psu.edu. [Last accessed on 2021 Aug 20].

10. Mogre V, Abanga ZO, Tzelepis F, Johnson NA, Paul CP Adherence to and factors associated with self-care behaviours in type 2 diabetes patients in Ghana. BMC Endrocrine Disorders. 2017;17(1):20. https://doi.org/10.1186/s12902-017-0169-3 PMid:28340613

11. Jacques $\mathrm{CH}$, Jones $\mathrm{RL}$. Problems encountered by primary care physicians in the care of patients with diabetes. Arch Family Med. 1993;2(7):739-41. https://doi.org/10.1001/archfami.2.7.739 PMid:8111499

12. Dalewitz J, Khan N, Hershey CO. Barriers to control of blood glucose in diabetes mellitus. Am J Med Qual. 2000;15(1):16-25. https://doi.org/10.1177/106286060001500104 


\section{PMid:10680221}

13. Drass J, Kell S, Osborn M, Bausell B, Corcoran JJr., MoskowitzA et al. Diabetes care for Medicare beneficiaries: Attitudes and behaviors of primary care physicians. Diabetes Care. 1998;21(8):1282-7. https://doi.org/10.2337/diacare.21.8.1282

\section{PMid:9702434}

14. Colaizzi PF. Psychological research as the phenomenologist views it. In: Valle RS, Mark K, editors. Existential Phenomenological Alternatives for Psychology. New York: Oxford University Press; 1978. p. 48-71.

15. Lugtenberg M, Burgers JS, Besters CF, Han D, Westert GP. Perceived barriers to guideline adherence: A survey among general practitioners. BMC Family Pract. 2011;22:98. https:// doi.org/10.1186/1471-2296-12-98

PMid:21939542

16. Brunk DR, Taylor AG, Clark ML, Williams IC, Cox DJ. A Culturally appropriate self-management program for Hispanic adults with type 2 diabetes and low health literacy skills. J Transc Nurs. 2017;28(2):187-194. https://doi. org/10.1177/1043659615613418 PMid:26525585

17. Chary A, Greiner M, Bowers C, Rohloff P. Determining adult Type 2 diabetes-related health care needs in an indigenous population from rural Guatemala: A mixed-methods preliminary study. BMC Health Service Res. 2012;22;476. https://doi. org/10.1186/1472-6963-12-476

18. Savoca M, Miller CK. Food selection and eating patterns: Themes found among people with type 2 diabetes mellitus. J Nutr Educ. 2001;33(4): 224-33. https://doi.org/10.1016/ S1499-4046(06)60035-3

PMid:11953244

19. Rubin RR. Adherence to pharmacologic therapy in patients with type 2 diabetes mellitus. Am J Med. 2005;118(5A):27S-34. https://doi.org/10.1016/j.amjmed.2005.04.012 PMid:15850551

20. Kennedy A, Narendran P, Andrews RC, Daley A, Greenfield SM. Attitudes and barriers to exercise in adults with a recent diagnosis of Type 1 diabetes: A qualitative study of participants in the exercise for type 1 diabetes (EXTOD) study. BMJ Open. 2018;8(1):1-9. https://doi.org/10.1136/bmjopen-2017-017813 PMid:29371269

21. Markowitz SM, Gonzalez JS, Wilkinson JL, Safren SA A review of treating depression in diabetes: Emerging findings. Psychosomatics. 2011;52(1):1-18. https://doi.org/10.1016/j. psym.2010.11.007

PMid:21300190

22. Puhl RM, Moss-Racusin CA, Schwartz MB, Brownell KD. Weight stigmatization and bias reduction: Perspectives of overweight and obese adults. Health Educ Res. 2008;23(2):347-58. https:// doi.org/10.1093/her/cym052

PMid: 17884836

23. Goffman ES. Notes on the Management of Spoiled Identity. Englewood Cliffs, NJ: Prentice-Hall; 1963.

24. Link BG, Phelan JC. Stigma and its public health implications Lancet. 2006;367(9509):528-9. https://doi.org/10.1016/ S0140-6736(06)68184-1 PMid: 16473129

25. PolonskyWH, FisherL, Guzman S, Villa-CaballeroL, Edelman SV. Psychological insulin resistance in patients with type 2 diabetes: The scope of the problem. Diabetes Care. 2005;28(10):2543-5. https://doi.org/10.2337/diacare.28.10.2543 PMid:16186296

26. Ong WM, Chua SS, Ng CJ. Barriers and facilitators to selfmonitoring of blood glucose in people with type 2 diabetes using insulin: A qualitative study. Patient Prefer Adherence. 2014;8:237-46. https://doi.org/10.2147/PPA.S57567 PMid:24627628

27. Ritholz MD, Smaldone A, Lee J, Castillo A, Wolpert $H$, Weinger K. Perceptions of psychosocial factors and the insulin pump. Diabetes Care. 2007;30(3):549-54. https://doi. org/10.2337/dc06-1755 PMid:17327319

28. Browne JL, Ventura A, Mosely K, Speight J. I call it the blame and shame disease: A qualitative study about perceptions of social stigma surrounding type 2 diabetes. BMJ Open. 2013;3(11):e003384. https://doi.org/10.1136/ bmjopen-2013-003384 PMid:24247325

29. Cardenas M, Miranda J, Beran D. Delivery of Type 2 diabetes care in low-and middle-income countries: Lessons from Lima, Peru. Diabetic Med. 2016;33(6):752-60. https://doi.org/10.1111/ dme.13099

PMid:27194174

30. Rushforth B, McCrorie C, Liz G, Midgley E, Foy R. Barriers to effective management of type 2 diabetes in primary care: Qualitative systematic review. Br J General Pract. 2016;66(643):e114-27. https://doi.org/10.3399/bjgp16X683509 PMid:26823263

31. Pati S, Pati S, Akker M, Schellevis FG, Sahoo KC, Burgers JS Managing diabetes mellitus with comorbidities in primary healthcare facilities in urban settings: A qualitative study among physicians in Odisha, India. BMC Fam Pract. 2021;22(1):99. https://doi.org/10.1186/s12875-021-01454-4

PMid:34022811 